\title{
The Medical School of the Catholic University of Croatia: Principles, Goals, Standards and Organization
}

\author{
Damir Sapunar ${ }^{1,2}$, Matko Marušić ${ }^{1}$, Livia Puljak ${ }^{1}$, Ivica Grković ${ }^{1}$, Mario Malički ${ }^{1}$, \\ Ana Marušićc , Marta Čivljak², Željko Tanjićn
}

${ }^{1}$ University of Split School of Medicine Split, Croatia, ${ }^{2}$ Catholic University of Croatia, Zagreb, Croatia
The aim of the study was to present the concept on which the School of Medicine at the Catholic University of Croatia (CUC) will be established. The new School will alleviate the shortage of physicians in Croatia and introduce an innovative form of medical education focused on principles of patient-centered care and social accountability. At the same time, the students will acquire all relevant competencies and levels of knowledge, skills and attitudes that are required by current evidence in medical education, European standards and guidelines for quality assurance at higher education institutions. The four pillars of the CUC Medical School are: 1) distributed medical education that involves health institutions outside major medical centers, 2) the concept of transformative learning, 3) teaching and practicing evidence-based medicine, and 4) implementation of quality management principles supported by information technology solutions for effective management of learning, research and practice. The overall aim of the CUC School of Medicine is to educate and train physicians capable of using best available medical evidence to deliver economically sustainable healthcare that can improve equity and health outcomes in the communities they serve, particularly those that are currently underserved. Conclusion. The proposed programme is introducing an original system of modern medical education that insists on develKey words: Medical education - Transfor- oping humanistic aspects of medicine, patient-centred care and social
mative learning - Social accountability - accountability, while maintaining all competencies and knowledge Patient-centered care - Longitudinal inte- levels that a physician should have according to the current undergrated community clerkship.

\section{Introduction}

Healthcare professionals represent the link between medical knowledge and population. They are the public face of a healthcare system and their education is essential for a well-functioning healthcare system (1). Healthcare systems worldwide are becoming more and more expensive and complex, and healthcare professionals are faced with ever increasing challenges, from the new risks of emerging infectious diseases to environmental pollution and risk behavior, all amplified by mass migrations and epidemiological changes in times when there are still large inequalities between and within countries and regions $(1,2)$.

Medical education lags behind these newly emerging health needs, primarily due to the fragmented, obsolete, and static 
medical curricula, which create inadequately educated physicians who have to deal in practice with problems quite different from those they learned about from the textbooks (3-5). Their competencies do not necessarily match patient and community health needs; they are not trained to work in teams; they do not consider potentials of specific technology in the context of current medical needs and economic possibilities; they do not provide systematic continuous care to their patients; they are oriented toward hospitals at the expense of family medicine; and they are unprepared to work on improving the healthcare system (1).

Awareness of the fact that healthcare professionals receive inadequate education has led to a range of changes, even revolutions, in medical education, but these efforts have not managed to overcome the weaknesses and inequalities of healthcare systems. The first revolution in medical education occurred at the beginning of the $20^{\text {th }}$ century when the medical curriculum started to rely on science (6). The introduction of clinical problem-based education in the mid- $20^{\text {th }}$ century marked the second revolution (7). Today, the third revolution is under way, based on systematic improvement of efficacy of healthcare systems through the adjustment of important professional competencies to specific contexts while relying on global knowledge (1). The gap between the requirements of modern science about medical education and medical curricula is also present in Croatia (8-11). The CUC Medical School may narrow this gap, because it would not be burdened by structural issues of the times passed $(5,12-15)$.

CUC medical school will advocate a special care for the community, the ill, the weak, and the underserved, ensuring that practical work and skill acquisition take priority. It will apply scientific knowledge resulting from progress in medicine and healthcare to teaching and to the local community, spreading academic atmosphere that will aim to reach even the most distant regions of Croatia. Scientific research will be focused primarily on the issues important for patients, followed by topics important for the community, public, and healthcare professionals (16).

The aim of the study was to present innovative concept of a new medical program that will be based on distributed medical education, transformative learning, teaching and practicing evidence-based medicine, and implementation of quality management principles supported by information technology.

\section{Grounds for launching a new medical school in Croatia}

The motive to launch the new medical school in Croatia was in part a response to the current shortage of medical physicians in Croatia (17), as well as the introduction of an innovative and modern system of medical education that fosters humanistic aspects of medicine, patient-centered care, and social accountability, while providing the competences and knowledge that current understanding of the medical education requires from future medical doctors.

The suggested transformation of medical education cannot be carried out through the existing institutions, because the state-funded academic community resists the change and persists in maintaining the present state of healthcare system and income through mechanisms of suboptimal staffing and decision-making (18). In such circumstances, internationally competitive institutions, designed in line with the state-of-the-art standards and not limited by the existing relations, have to be built from the scratch.

The CUC School of Medicine will be a non-profit institution, open to all eligible individuals worldwide. Its main goal will be to create a different profile of physicians, 
who will be recognized by their respect for patients and orientation toward non-privileged, underserved and underdeveloped regions. The CUC School of Medicine will strive to increase the sense of social accountability in future physicians according to the Consensus for Social Accountability of Medical Schools (19-21), while providing them with the best scientific and research education. The development of the awareness of the need for community-oriented work and lifelong learning, including postgraduate education, will be an integral part of their medical education. In order to reach these goals, outcome competencies will be clearly defined. The focus of teaching will be on the acquisition and development of competencies through learning by doing, i.e. through practical work with patients and scientific research directed at investigating and promoting the patient-health system relationship, and future development of evidence-based medicine.

The shortage of physicians in Croatia, especially its rural areas, justifies the need for opening a new medical school $(17,22-25)$. On the list of countries ranked by physician density, Croatia is ranked $34^{\text {th }}$ in Europe, with 259 physicians per 100,000 population. European average is 331 physicians per 100,000 population. Therefore, the number of physicians in Croatia is $22 \%$ below the European average. To reach the European average, Croatia needs additional 3280 physicians. If the annual average rate of increase in the number of physicians was 3 physicians per 100,000 population, as it was in 2009, it would take 24 years for Croatia to reach that goal $(17,22)$.

Physicians are needed in many poor and underdeveloped areas in the world (1), and the strategic option for a medical school would be to sponsor students from such areas and provide them with free education. Furthermore, the CUC School of Medicine would be particularly welcoming to Croats living abroad, by enabling them to study in their old homeland, becoming closer to local people, and earning a globally recognized degree.

\section{Organizational structure: four pillars of the CUC School of Medicine}

The four pillars of the CUC School of Medicine (Figure 1) include the following set of principles: a) distributed medical education, i.e. carrying out teaching activities outside of major medical centers and bringing academic atmosphere to even the most remote communities, where students would receive most of their practical training, b) transformative learning, to help future physicians to actively participate in the transfer of the modern medicine achievements to their communities, c) teaching and practicing evidence-based medicine, and d) quality management principles supported by information technology solutions for effective management of learning, research and practice, as well as for monitoring/evaluation of the progress.

Patient-centered care and social accountability are the central and most important values on which the CUC School of Medicine is built upon. In recent years, an increasing number of medical schools have accepted the concept that medical education is not only an "assembly line" for the production of new physicians (26). The CUC School of Medicine will incorporate social accountability standards into medical education (27). The Catholic identity of the School will be reflected in cultivating the highest and most noble principles of compassion and care for vulnerable populations and in providing an academic platform where various sciences and professions are explored through perspective of the Christian understanding of the world reality as a whole and humans in particular. The CUC School of Medicine will give highest priority 


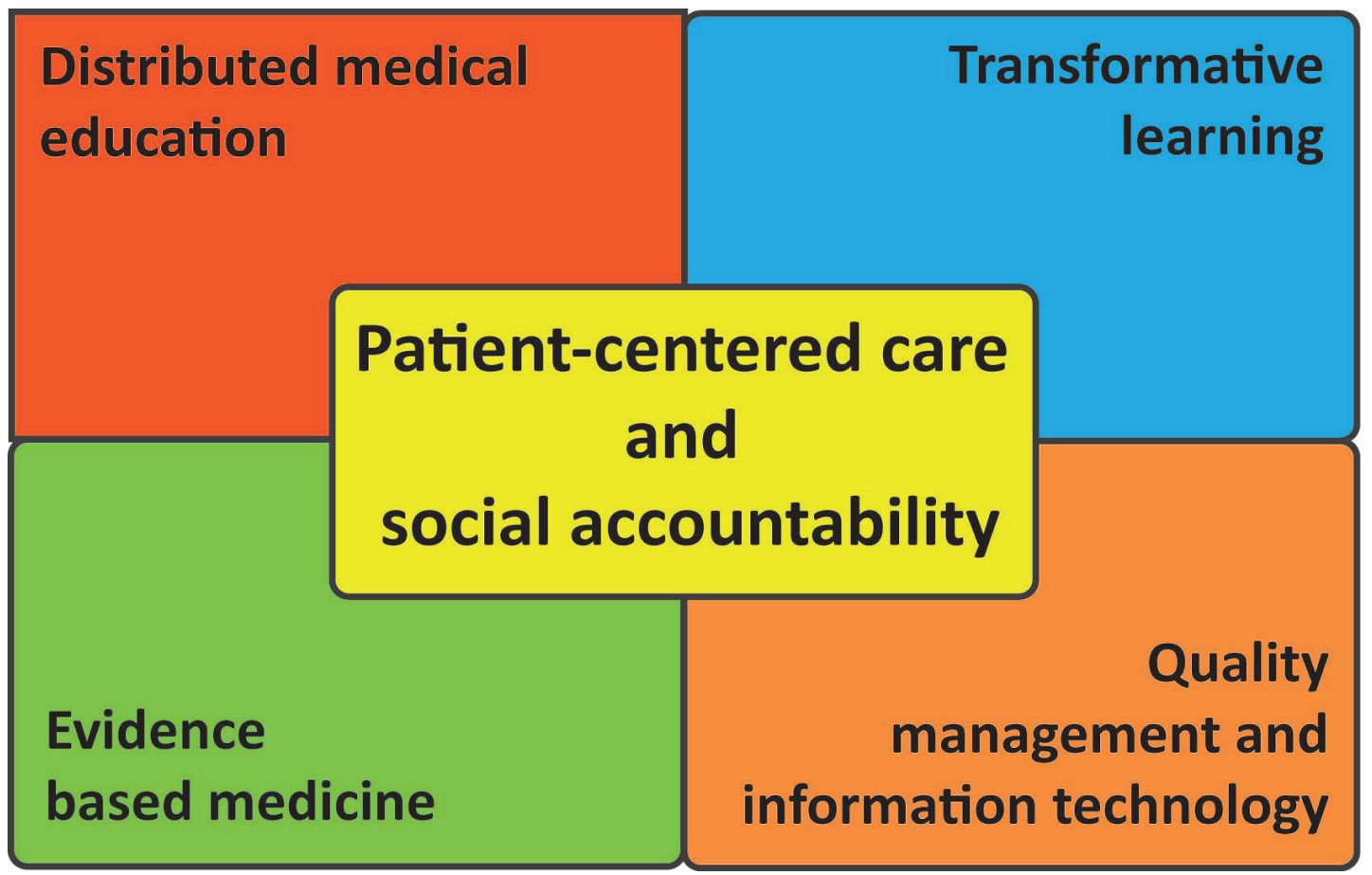

Figure 1. The main determinants of the CUC Medical School organization.

to the development, study, and promotion of the interests of patients and communities and thus, by teaching and setting an example, prevent alienation, commercialization, profiteering, and neglecting the sacredness of life and human dignity in medicine and healthcare. Patient-centered care and social accountability include adequate training in communication skills, medical humanities, and joint patient-physician decision making, while using the best evidence available from the literature in addition to education in social medicine and palliative care (1). Education will rely on particular field-work conditions and involve small hospitals, family medicine practices, and other stakeholders (28).

This focus will be reflected in volunteering and charity work as an integral part of educational process; "verticalization" of medical humanities - i.e. inclusion of medical humanities topics in all years of medical education, which requires the adoption of general principles of treating and commu- nicating with patients; and a large part of the curriculum dedicated to global, social, and palliative medicine. The overall aim is to teach medical students to approach patients with empathy while applying the most recent medical knowledge and technology.

\section{Distributed medical education}

The CUC School of Medicine will not have a centralized educational setting. For the first two years, theoretical teaching will mostly be carried out in Zagreb, Croatia, where the CUC is located. Afterwards, students will be distributed to healthcare institutions across Croatia according to the established and carefully planned schedule (29). Thus, students will develop their professional competencies through working with patients in smaller, rural communities, in a specific context of everyday provision of healthcare, and through partnership with local physicians-teachers while using the principles of evidence-based medicine (28). 
Not many medical schools in the world provide medical and healthcare education in small provincial hospitals, family medicine practices, and other healthcare institutions in remote areas $(28,30-38)$. The contact with patients will be based on the concept of continuous integrated community clerkship (39-42). The traditional block clerkship, where students acquire clinical experience in a single discipline, has received criticism due to the lack of continuity and inability to follow up the entire process of patient treatment, which leads to the collapse of the concept of patient-centered care $(42,43)$. Integrated community clerkship is an innovative solution for the limitations of classic clinical clerkship $(44,45)$.

In CUC concept, a student, who is a clinical clerk, has two mentors - a course mentor, supervising all the students taking his or her course, and a field mentor, taking care of the practical training of individual students. The course mentor communicates with both students and their field mentors using etechnology, evaluates the work of each student and field mentor, keeps records, and administers the exam. The field mentor evaluates practical knowledge of the student, supervises the student's weekly progress in mastering required tasks, and logs reports on student's work into the student's individual portfolio to the course mentor using e-technology.

After a short block of lectures and seminars, the students will be divided into small groups of 2-3 students, and sent to their clinical workplaces outside major medical centers, where they will participate in providing medical care and acquire skills specified by the healthcare program, under the supervision of their field mentor, who they accompany during his or her daily work routine, including on-call shifts. During this practical part of clinical clerkship, each student will have to follow up continually several patients and describe their treatments in the form of writing tasks based on EBM cases (46). The EBM-based writing tasks have to be sent for evaluation and feedback by e-technology to the course mentor, who is usually an experienced and internationally recognized expert. After receiving the course mentor's feedback, each student will present his or her work to the local team. This process includes a three-way exchange of knowledge, where medical procedures carried out by junior mentors/physicians in rural areas are being constantly reviewed.

Selected institutions in small communities will provide clinical training to a limited number of medical students upon signing a collaboration agreement. By signing the agreement, such an institution, which will act as a teaching affiliate, becomes an affiliate institution of the CUC.

In addition to the usual programs of student exchange, e.g. Erasmus exchange program (47), the curriculum involves volunteering in social and healthcare institutions and extensive summer training abroad in both developed and poor regions. The latter will be organized in cooperation with Catholic missions in developing countries.

Providing accommodation to students during their field training is feasible because the number of enrolled students will be small and only a few of them will be at the same place at the same time. Their accommodation will be arranged by the CUC in cooperation with affiliate institutions, and covered from tuition fees.

\section{Transformative learning}

Transformative learning is the expected outcome of the CUC medical curriculum. It requires students to face healthcare problems in a real setting and use the current internationally recognized concepts of successful treatment and care provision. The concept of transformative learning (Table 1) relies on changing the existing beliefs and ways 
Table 1. Characteristics of the three systems of medical education*

\begin{tabular}{|c|c|}
\hline Informative and formative learning & Transformative learning \\
\hline Memorizing & $\begin{array}{l}\text { Search, analysis, and synthesis of information to help with decision } \\
\text { making }\end{array}$ \\
\hline Professional acknowledgment & $\begin{array}{l}\text { Acquiring key competences needed for efficient team work in } \\
\text { healthcare system }\end{array}$ \\
\hline Ready acceptance of educational models & Creative adjustment of global achievements to local priorities \\
\hline Isolated systems of education and healthcare & Harmonized systems of education and healthcare \\
\hline Lonely institutions & Networks, alliances, and consortiums \\
\hline Strictly institutional issues & $\begin{array}{l}\text { Taking over global flows of educational material, teaching options and } \\
\text { innovations }\end{array}$ \\
\hline
\end{tabular}

${ }^{*}$ According to reference (1).

Table 2. Elements of medical education reform serving as the foundation for the medical school design*

\begin{tabular}{l}
\hline Introducing a competence-based education plan. \\
\hline Including competences in the processes of quickly changing local settings while relying on global sources. \\
\hline $\begin{array}{l}\text { Encouraging education within a profession and between professions, breaking professional chains, and stimulating } \\
\text { cooperative and non-hierarchical relationships within teams. }\end{array}$ \\
\hline Information technology use in learning. \\
\hline Investing in teaching equipment and continuing teaching education. \\
\hline Stimulating new types of professionalism, where competencies are taken as objective criteria for the evaluation of \\
healthcare professionals and values built around the social accountability. \\
\hline $\begin{array}{l}\text { Turning academic centers into systems encompassing a network of hospitals and primary care facilities interconnected } \\
\text { into global alliances. }\end{array}$ \\
\hline Breeding the culture of critical thinking.
\end{tabular}

*According to (1).

of thinking through conversation and critical analysis in a real setting, with the aim to develop managerial competencies in active problem solving $(48,49)$. To fulfill this role, students and their mentors should have adequately developed professional competencies, ethical norms, and social accountability of locally accountable and globally connected teams (1). Thereby, the medical school will base its design and curriculum on the previously mentioned innovative principles, adjusting them to the current standards in defining student competencies (Table 2).

\section{Evidence-based medicine}

Evidence-based medicine (EBM) encompasses the best evidence in the literature, experience of healthcare professionals, and values and needs of patients $(50,51)$. For problem-solving in healthcare, one should look for evidence considered to have the highest level in the hierarchy of evidence in medicine, such as randomized controlled trials (RCTs) and systematic reviews. Results of systematic reviews are helping make informed decisions about the treatment of individual patients, making strategic and other decisions in medicine and healthcare. Not only that such scientific knowledge improves technology, but it also empowers general population. People become more informed and more aware of their healthcare needs and rights and more able to make decisions on their lifestyle changes $(52,53)$.

Within their EBM training, healthcare professionals should adopt the practice of shared-decision making, where the patient 
and healthcare professionals together consider the advantages and disadvantages of available treatment options, with an aim of choosing the model of care in line with patient's wishes $(54,55)$.

EBM and shared decision-making will be practiced and taught at the CUC School of Medicine from the first year on, together with the traditional training in biostatistics, informatics, and research methodology in medicine, because these are the foundations of EBM. Gradually, EBM will be included in all student tasks to serve as a foundation for student's explanations, conclusions, and course of action.

\section{Quality management and information technologies (IT)}

European standards and guidelines for quality assurance in higher education area are applicable to all higher education institutions in Europe, irrespective of their organization, function, size, or national system within which they operate (56). These standards require the following:

1. A culture that recognizes and stimulates the development of quality management strategy, rules, and procedures.

2. Formal and publicly accessible mechanisms of periodical supervision of quality management system.

3. Evaluation of student knowledge and competencies in accordance with the announced criteria, rules, and procedures.

4. Availability of appropriate and competent teaching staff whose credentials may be checked by external control.

5. Availability of the equipment and conditions for studying.

6. Information system for the collection, analysis, and use of all information needed for effective management of study programs and all other related activities.

7. Regular publication of objective information on the programs (56).
Accordingly, the CUC Medical School will ensure quality management by using a business process management system that allows for designing, modeling, describing, and documenting all intra-institutional business processes, identification of responsible persons and services and related documents and software (57). Each procedure will have a clearly defined structure, process, and outcome, usually associated with data archiving (58). Such a description of business processes allows for the use of information technology in any process, and such a system of quality management allows for the use of PDCA (plan-do-check-adjust) approach (59) in any aspect of any work. The aim of such approach is ensuring permanent improvement and advancement according to the results and changes within an institution, and serving as a landmark and gold standard for assessment of work and quality (57).

\section{The CUC medical curriculum}

The main structure of the curriculum was developed in line with the recommendations in the Directive 2005/36/EC of the European Parliament and of the Council (60), the World Federation for Medical Education's revised standards for basic medical education $(61,62)$, and the global independent Commission's Education of Health Professionals for the 21st century (63).

The CUC medical curriculum fully implements all four recommendations from the Directive 2005/36/EC of the European Parliament and of the Council regarding the recognition of professional qualifications as of September 07, 2005 (60) and provisions of the Act on Regulated Professions and Recognition of Foreign Professional Qualifications (64) as follows: a) appropriate scientific medical knowledge and good understanding of scientific methods, including the principles of biological functions and evalu- 
Table 3. Specific characteristics of the medical school curriculum

Preclinical courses are reduced and parts of teaching material related to clinical issues are integrated with clinical course at later years.

Vertical integration of modules enabling students to approach clinical problems in a scientific manner, taking into account the principles of evidence-based medicine.

Clinical skills, as defined in clinical skill catalogue, are learned by doing (hospital internship); practical work on models starts at the first year and involves early contact with patients in family medicine offices and adequate skill catalogue.

Strongly stimulating all forms of student exchange. Mission trips will be organized for senior students to gain practical knowledge and develop a moral profile adequate for this demanding and noble profession.

Introducing students to global health topics, especially poverty-related diseases, will lead to activities aimed at reducing inequalities in access to healthcare.

The medical school will largely rely on the system of evaluation and acknowledgment of learning outcomes achieved through extracurricular and informal activities, primarily volunteering and charity work.

ation of scientifically established facts and data analysis, b) sufficient understanding of the structure, function, and behavior of the healthy and ill people and relationship between an individual's health condition and his or her physical and social setting, c) appropriate knowledge of clinical disciplines and procedures, which ensures having a complete view of mental and physical conditions, knowledge of medical prevention, diagnosis, and treatment and human reproduction, and d) appropriate clinical experience in hospitals under appropriate supervision. Among the learning outcomes, the priority will be given to the acquisition of practical knowledge and skills, which have been insufficiently represented in teaching programs of existing medical schools in Croatia (65).

Compared to the current program of medical schools in Croatia, the proposed curriculum is reduced to avoid overburdening the students with huge amounts of learning material, especially in the case of preclinical courses (Table 3 ). The traditional way of organizing courses in Croatian medical school assumes a division of teaching units based on the classical departments of medical schools represented by classical subjects (e.g. Anatomy, Physiology, etc.). This concept where each departments is responsible for its course, disallowed any co- operation between teachers of different departments, while the fight for the dominant position between individual departments led to unnecessary expansion of individual classes by overburdening them with unnecessary facts and consequent redundancy in course contents.

The CUC curriculum applies horizontal integration of these courses primarily based on the division into organ systems. A similar concept has been applied at Croatian medical schools only in the case of the nervous system, where the structure and function of the nervous system are integrated in the Neuroscience course. Unfortunately, no integration has been implemented for other organ systems, despite the fact that the integration in the Neuroscience course showed to be effective.

The classes will be given in Croatian or English; both languages will be equally acceptable. For students who do not speak both languages, an intensive language course will be organized. The reasons for giving lectures in English in addition to Croatian include the wider range of textbooks available in English, participation of foreign experts in teaching, and enrollment of foreign students. However, knowledge of the Croatian language is required for clinical work involving patients. 


\section{Courses}

The CUC School of Medicine will last six years and include 5,500 hours of direct teaching and 360 European Credit Transfer System (ECTS) points. The classes will be organized in 10 symmetrically arranged modules (similar courses/subjects will be grouped), with each module consisting of one or more courses. There will be a total of 24 courses, including two vertical courses (Medical Humanities and Research in Biomedicine and Health) running through all six years (Figure 2). All courses will consist of 200 teaching hour, except for the vertical ones, which will consist of 275 hours. The last semester will be dedicated to research only and will result in an undergraduate thesis.

\section{Testing student knowledge and competencies}

Student knowledge in any subject area will be tested using a unified approach. The final evaluation will consist of three components: continuous evaluation during courses, practical and written exam at the end of the course. Written exams will be centralized and carried out in the form of online assessments.

Continuous evaluation will be performed using different testing modalities. At the end of each course, students will have to take an exam consisting of a practical and a written component. The final grade will be calculated according to a predefined formula, which will be identical for each exam. A practical

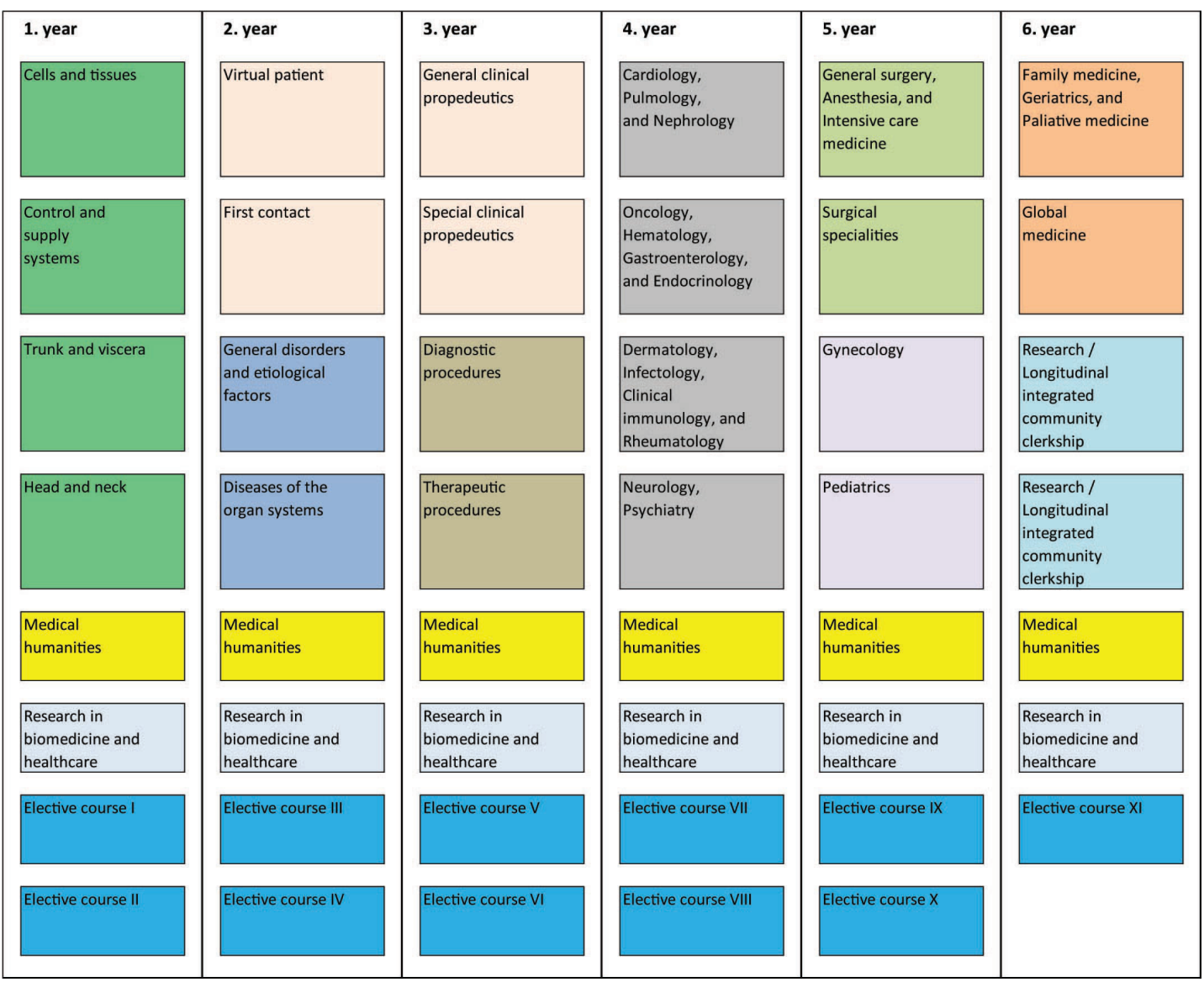

Figure 2. Organization of modules and courses taught at the medical school. Each module is color-marked and consists of several thematically-related courses. Each cell represents one course. 
test as a part of the exam will be a part of courses where practical skills are relevant, and account for $30 \%$ of the grade. Written test will account for $30 \%$ of the grade and the remaining $40 \%$ of the grade will be based on continuous knowledge tested during courses. All scores will be recorded and kept in a student's e-portfolio.

\section{Integrated exams}

The purpose of integrative exams is to help students regularly reiterate what they learned (66), discourage last-minute cramming, and classify students according to their academic success (in percentiles), which will make a significant part of the Diploma Supplement. The Exam results also provide the feedback on the quality of teaching of individual courses, i.e., reliability of grades earned by the students.

Integrative exams include a) objective, structured, clinical examinations (OSCE) and b) two aggregate knowledge exams (AKE) at the end of the third and sixth year of the studies. AKE I and AKE II are multiple-choice exams consisting of 200 questions each. The number of questions from each course is proportional to the number of course hours in the respective period (67).

OSCE is an exam comprised of multipole "stations" designed to test clinical skill performance. Skills are defined in a Clinical Skills Catalogue. Stations are designed and their order organized to test the performance of each skill, or a group of simple skills, within a given period. An OSCE examination usually consists of 10 stations (67).

\section{Graduate thesis}

The work required to write an undergraduate thesis reflects a practical use of knowledge acquired during previous years of studies. A graduate thesis at the CUC School of Medicine will have to be based on original research work, including systematic reviews and meta-analyses. Students will work on their thesis-related research after having defined their research plan during the $5^{\text {th }}$ year course "Research in Medicine and Healthcare".

A student will be able choose a mentor and the topic of the thesis and start with the thesis-related research as early as the first year, but will have to have a mentor and thesis topic chosen by the start of the "Research in Medicine and Healthcare" course at the fifth year. The thesis research plan will be evaluated and students/mentors will receive feedback about the plan, and if necessary, suggestions for improvement of the plan. All graduate theses will be published in English in the openly-available institutional repository.

By developing their undergraduate theses, students will acquire competencies in research methodology, collection, analysis and presentation of data, and public presentation and defense of the thesis. Students will also be trained in writing a research paper in English, selection of a suitable journal, writing a cover letter for the editor, and stimulated to send the manuscript based on a thesis to a scholarly journal. Graduate theses will be evaluated for their quality, presentation, and defense (68).

\section{Students}

The enrollment criteria will be defined in line with the social accountability of the CUC School of Medicine and needs of the society. A three-member committee independently decides on whether or not to enroll a student based on the student's highschool grades, motivational letter, curriculum vitae, and an interview. We will enroll 340 students each year, which ensures that each student receives appropriate attention and mentoring. A counseling system for students will be organized, in order to follow 
their academic success, as well as their social and personal needs.

\section{Faculty}

The faculty teaching at the medical school will be divided into four groups. The core teaching faculty will be composed of experienced teachers holding academic positions, who will be employed as either full- or parttime faculty. They will be module coordinators and teach according to the CUC direct hour teaching requirements for teachers holding specific positions.

The second group are physicians working in general hospitals and other healthcare institutions in smaller communities that will participate in teaching clinical courses. They will be in charge of practical teaching and will be engaged through collaboration agreements. In Croatia, there are many healthcare institutions that are not a part of university centers but employ physicians whose professional quality does not lag behind that of their colleagues working in major university hospital centers. Although we cannot corroborate this statement with objective evidence, the opposite would imply that the healthcare system admits to the fact that population living outside larger cities is provided with healthcare of lower quality. Healthcare institutions that sign the collaboration agreement will engage an appropriate number of physicians to carry out the practical part of teaching. The third group of faculty will include young physicians who opt for academic career after graduation. They will be employed as instructors through teaching contracts. This category will serve as a potential source of future core faculty. The fourth group will include qualified Croatian physicians from abroad and foreign experts who will participate in teaching. The faculty will primarily be selected based on their excellence in academic medicine - research, teaching and practice (69).
According to the relevant legal provisions and the CUC Statute, the faculty will regularly be evaluated for their teaching, professional, and research work and results. The cooperation with external teaching sites and partner schools will be formalized through official agreements and contracts.

\section{Research}

Every higher education institution must have an adequate research activity because higher education and research cannot be separated. This is particularly important in medicine, where the triad of research, practice and teaching is the core of academic medicine. At the existing medical schools in Croatia, research has rarely been the result of a clear national, university or school strategy. The strategies that were adopted were often not implemented, and the research activity of those institution emerged as a result of the scientific interest of leading scientists in the institution, i.e. it was mainly the result of their international scientific cooperation or the result of the scientific interest of the group in which they pursued their post-graduate training. The result of such a neglect of strategic documents is the fragmentation of the scientific community in Croatia, inability to form larger research groups, poor utilization of research equipment, and poor competitiveness on the international research scene. Our Research carried out at the CUC School of Medicine will engage students as researchers and focus on research questions important for patients, public, and healthcare professionals alike (16). The first research objective of the CUC School of Medicine will be to develop an active collaboration with the Cochrane collaboration, which offers great opportunities for scientific and professional work at the international level. We hope that the collaboration with the Cochrane will help us develop methodological excellence in 
research. Focus on meta-research is also important because it will also provide excellent opportunities for high quality research in conditions where the infrastructure for clinical or preclinical research is not yet developed. Finally, research on evidence synthesis can be a distributed effort, which will allow active participation of all CUC teachers/researchers regardless of their actual location (CUC premises or a local hospital).

As the CUC School of Medicine will be firmly anchored in the social science and humanities foundation of the CUC, we will focus our research activity also on social aspects of medicine, primarily on medical education and science and health policy. One of the reasons to focus on these topics is that there are many medical education, or health care policy, reforms but they are rarely systematically and rigorously evaluated. We plan to use such approach to follow and assess the impact of the new medical curriculum developed at CUC to test the value of the medical education concept presented in this article.

\section{Conclusion}

It should be mentioned that none of the programme's characteristics mentioned above that we consider worthy of describing here are original. For example, integration of subjects has already been applied by many universities. Distributed medical education is also a model used by many medical schools. However, what makes this programme original is the selection and combination of characteristics and their application in a specific Croatian context.

What is already known on this topic

Awareness of the fact that healthcare professionals receive inadequate education leads to changes in medical education. However, medical education lags behind newly emerging health needs, primarily due to the fragmented, obsolete, and static medical curricula.

\section{What this study adds}

The study presents the concept for a new medical school, based on distributed medical education, transformative learning, teaching and practicing evidence-based medicine, and implementation of quality management principles supported by information technology.

Acknowledgment: The concept of the CUC Medical School described in this manuscript is based on the joint work of a team of experts at the initiative of Damir Sapunar, formed in late 2013. The team was formed by Damir Sapunar and Matko Marušić, joined by Ivica Grković, Livia Puljak, Mario Malički and Ana Marušić. The official document on the founding idea was sent to the Catholic University of Croatia on November 25, 2013. After the idea was generally accepted at the University, the team prepared a study on the founding of the Study and donated it to the CUC. On the part of the CUC, the rector of the CUC Željko Tanjić and Marta Čivljak played a key role in the planning of the Study. The final decision on establishing the School was made at the Senate of the CUC on April 10, 2018. This article is a summary of the Study on Establishing School of Medicine at the CUC, available on the Study Web Site.

Authors' contributions: Conception and design: DS and MMar; Acquisition, analysis and interpretation of data: DS, MMar, LP, IG, and AM; Drafting the article: DS; Revising it critically for important intellectual content: LP, IG, MM, AM, MČ, and ŽT; Approved final version of the manuscript: DS, MMar, LP, IG, MM, AM, MČ, and ŽT.

Conflict of interest: The authors declare that they have no conflict of interest.

\section{References}

1. Frenk J, Chen L, Bhutta ZA, Cohen J, Crisp N, Evans $\mathrm{T}$, et al. Health professionals for a new century: transforming education to strengthen health systems in an interdependent world. Lancet. 2010;376(9756):1923-58.

2. Dwyer-Lindgren L, Bertozzi-Villa A, Stubbs RW, Morozoff C, Kutz MJ, Huynh C, et al. US countylevel trends in mortality rates for major causes of death, 1980-2014. JAMA. 2016;316(22):2385-401.

3. Awasthi S, Beardmore J, Clark J, Hadridge P, Madani H, Marusic A, et al. Five futures for academic medicine. PLoS medicine. 2005;2(7):e207.

4. Marušić A, editor. Revitalization of academic medicine. Zagreb: Medicinska naklada; 2005.

5. Grkovic I, Sapunar D, Marusic M. Ways to address the challenges of a modern medical cur- 
riculum: living academic medicine at the University of Split, School of Medicine. Acta Med Acad. 2012;41(1):7-17.

6. Flexner A. Medical education in the United States and Canada: A Report to the Carnegie Foundation for the Advancement of Teaching. Boston: The Merrymount Press; 1910.

7. Barrows H, Tamblyn R. Problem-based learning: an approach to medical education. Medical Education. New York: Springer Publishing Company; 1980.

8. Marusic M, Sapunar D. Reasons for founding a University of Split Medical School [in Croatian]. Lijec Vjesn. 1996;118(5-6):133-8.

9. Sapunar D, Marusic M. The curriculum plan for the Split University Medical School--a modern concept for a new school [in Croatian]. Lijec Vjesn. 1999;121(6):208-12.

10. Puljak L, Sapunar D. Turning Croatian science into policy. Croat Med J. 2008;49(2):155-7.

11. Puljak L, Vukojevic K, Lovric Kojundzic S, Sapunar D. Assessing clinical and life sciences performance of research institutions in Split, Croatia, 2000-2006. Croat Med J. 2008;49(2):164-74.

12. Koceic A, Mestrovic A, Vrdoljak L, Vukojevic K, Barac-Latas V, Drenjancevic-Peric I, et al. Analysis of the elective curriculum in undergraduate medical education in Croatia. Med Educ. 2010;44(4):387-95.

13. Maslov Kruzicevic S, Barisic KJ, Banozic A, Esteban CD, Sapunar D, Puljak L. Predictors of attrition and academic success of medical students: a 30-year retrospective study. PloS one. 2012;7(6):e39144.

14. Vrdoljak L, Mijacika T, Milicevic T, Sapunar D, Puljak L. Impact of a recruitment campaign on students' applications to medical school. Acta Med Acad. 2013;42(1):32-40.

15. Tesija RA, Maslov Kruzicevic S, Banozic A, Esteban CD, Sapunar D, Puljak L. Impact of extended course duration and stricter study organization on attrition and academic performance of medical students. Croat Med J. 2013;54(2):192-7.

16. Evans I, Thornton H, Chalmers I, Glasziou P. Testing Treatments - Better research for better healthcare. Padstow: TJ International Ltd.; 2011.

17. OECD / European Observatory on Health Systems. Croatia: Country Health Profile 2017. Brussels: OECD Publishing/European Observatory on Health Systems and Policies; 2017. [cited 2018 March 20] Available from: http://dx.doi. org/10.1787/9789264283312-en.

18. Babic A, Brekalo M, Juric S, Puljak L. Pressures and interventions imposed on medical school teachers regarding students' examination grades. Med Educ. 2013;47(8):820-3.

19. Boelen C, Heck JE. Defining and measuring the social accountability of medical school. Geneva: World Health Organization. Division of Development of Human Resources for Health: 1995. [cited 2018 March 20] Available from: http://www.who. int/iris/handle/10665/59441.

20. Global Consensus for Social Accountability of Medical Schools. [homepage on the internet] East London, South Africa: GCSA Steering Committee [cited 2018 March 21]. Available from: http:// healthsocialaccountability.org/.

21. Lindgren S, Karle H. Social accountability of medical education: aspects on global accreditation. Med Teach. 2011;33(8):667-72.

22. Smoljanović M, Smoljanović A, Bočina I, Trošelj M, M. T. Relationship between the number of doctors and nurses in Europe with the gross national product (BNP) and health care expenditure at the beginning of the third millennium [in Croatian]. Hrvatski časopis za javno zdravstvo. 2009;5(18).

23. Drakulić V, Bagat M, Golem AZ. Regional distribution of physicians in Croatia [in Croatian]. Lijec Vjesn. 2009;131(11-12):301-5.

24. Kolcic I, Cikes M, Boban K, Bucan J, Likic R, Curic $\mathrm{G}$, et al. Emigration-related attitudes of the final year medical students in Croatia: a cross-sectional study at the dawn of the EU accession. Croat Med J. 2014;55(5):452-8.

25. Čipin I, Smolić Š, Vlah Jerić S. Demographic atlas of Croatian medical doctors [in Croatian]. Sveta Nedelja: Hrvatska liječnička komora; 2017.

26. Larkins SL, Preston R, Matte MC, Lindemann IC, Samson R, Tandinco FD, et al. Measuring social accountability in health professional education: development and international pilot testing of an evaluation framework. MedTeach. 2013;35(1):3245.

27. Boelen C, Dharamsi S, Gibbs T. The social accountability of medical schools and its indicators. Educ Health (Abingdon). 2012;25(3):180-94.

28. Jercic M, Cizmic Z, Vujevic M, Puljiz T. Practical training in family medicine in the Dalmatian hinterland: first-hand experience of four physicians. Acta Med Acad. 2012;41(1):93-9.

29. Sapunar D, Grkovic I, Luksic D, Marusic M. Management of teaching processes using the Share point platform: A case study from the University of Split School of Medicine. Acta Med Acad. 2016;45(1):34-8.

30. Verby JE. The Minnesota Rural Physician Associate Program for medical students. J Med Educ. 1988;63(6):427-37. 
31. Hansen LA, Talley RC. South Dakota's third-year program of integrated clerkships in ambulatorycare settings. Acad Med. 1992;67(12):817-9.

32. Anderson AS, Martell JV. Comparing sequential clerkships and a longitudinal clerkship for thirdyear medical students. Acad Med. 1994;69(5):4189.

33. Worley P, Silagy C, Prideaux D, Newble D, Jones A. The parallel rural community curriculum: an integrated clinical curriculum based in rural general practice. Med Educ. 2000;34(7):558-65.

34. Schauer RW, Schieve D. Performance of medical students in a nontraditional rural clinical program, 1998-99 through 2003-04. Acad Med. 2006;81(7):603-7.

35. Tesson G, Hudson G, Strasser R, Hunt D. Making of the Northern Ontario School of Medicine: A Case Study in the History of Medical Education. Montreal; Kingston; London; Ithaca: McGillQueen's University Press; 2009. [cited 2018 March 20] Available from: http://www.jstor.org/stable/j. ctt8052n.

36. Norris TE, Schaad DC, DeWitt D, Ogur B, Hunt DD. Longitudinal integrated clerkships for medical students: an innovation adopted by medical schools in Australia, Canada, South Africa, and the United States. Acad Med. 2009;84(7):902-7.

37. Strasser R, Hirsh D. Longitudinal integrated clerkships: transforming medical education worldwide? Med Educ. 2011;45(5):436-7.

38. Couper I, Worley PS, Strasser R. Rural longitudinal integrated clerkships: lessons from two programs on different continents. Rural Remote Health. 2011;11(2):1665.

39. Ogur B, Hirsh D, Krupat E, Bor D. The Harvard Medical School-Cambridge integrated clerkship: an innovative model of clinical education. Acad Med. 2007;82(4):397-404.

40. Hirsh DA, Ogur B, Thibault GE, Cox M. "Continuity" as an organizing principle for clinical education reform. N Eng J Med. 2007;356(8):858-66.

41. Hirsh D, Gaufberg E, Ogur B, Cohen P, Krupat E, Cox M, et al. Educational outcomes of the Harvard Medical School-Cambridge integrated clerkship: a way forward for medical education. Acad Med. 2012;87(5):643-50.

42. Ellaway R, Graves L, Berry S, Myhre D, Cummings BA, Konkin J. Twelve tips for designing and running longitudinal integrated clerkships. Med Teach. 2013;35(12):989-95.

43. Hudson JN, Weston KM, Farmer EA. Engaging rural preceptors in new longitudinal community clerkships during workforce shortage: a qualitative study. BMC Family Practice. 2011;12:103.
44. Hauer KE, O'Brien B, Poncelet AN. Longitudinal, integrated clerkship education: better for learners and patients. Point. Acad Med. 2009;84(7):821.

45. McLaughlin K, Bates J, Konkin J, Woloschuk W, Suddards CA, Regehr G. A comparison of performance evaluations of students on longitudinal integrated clerkships and rotation-based clerkships. Acad Med. 2011;86(10 Suppl):S25-9.

46. Sayre JW, Toklu HZ, Ye F, Mazza J, Yale S. Case Reports, Case Series - From Clinical Practice to Evidence-Based Medicine in Graduate Medical Education. Cureus. 2017;9(8):e1546.

47. Erazmus programe [homepage on internet] European Commission [cited 2018 March 20] Available from: http://www.erasmusprogramme.com/.

48. Mezirow J. Transformative dimension of adult learning. San Francisco: Jossey-Bass; 1991.

49. Mezirow J. Understanding transformation theory. Adult Education Quarterly. 1994;44(4):222-32.

50. Hatala R, Guyatt G. Evaluating the teaching of evidence-based medicine. JAMA. 2002;288(9):11102.

51. Straus SE, Green ML, Bell DS, Badgett R, Davis D, Gerrity M, et al. Evaluating the teaching of evidence based medicine: conceptual framework. BMJ. 2004;329(7473):1029-32.

52. Puljak L, Sambunjak D. Cochrane systematic review as a PhD thesis: an alternative with numerous advantages. Biochemia Medica 2010;20(3):319 26.

53. Puljak L, Sapunar D. Acceptance of systematic review as a thesis: survey of biomedical doctoral programs in Europe. Systematic Reviews. 2017;6:253.

54. Elwyn G, Laitner S, Coulter A, Walker E, Watson $\mathrm{P}$, Thomson R. Implementing shared decision making in the NHS. BMJ. 2010;341:c5146.

55. Vucemilovic M, Mahmic-Kaknjo M, Pavlicevic I. Transition from paternalism to shared decision making - a review of the educational environment in Bosnia and Herzegovina and Croatia. Acta Med Acad. 2016;45(1):61-9.

56. European Association for Quality Assurance in higher Education - ENQA. Standards and Guidelines for Quality Assurance in the European Higher Education Area. 2015. [cited 2018 March 20] Available from: http://www.enqa.eu/wp-content/ uploads/2015/05/ESG_endorsed-with-changedforeword.pdf.

57. Sapunar D, Grković I, Lukšić D, Marušić M. Business process management program for successful quality management and organization in medical schools. Acta Med Acad 2016;45(1):26-33. 
58. Donabedian A. Evaluating the quality of medical care. Milbank Q. 2005;83(4):691-729.

59. Moen RD, Norman CL. Clearing up myths about the Deming cycle and seeing how it keeps evolving. Quality Progress. 2010;11:22-8.

60. Directive 2005/36/EC of the European Parliament and of the Council. 2005 [cited 2015 March 20]. Available from: http://eur-lex.europa.eu/legalcontent/HR/TXT/?uri=CELEX:32005L0036.

61. WFME. Task Force on Defining International Standards in Basic Medical Education. Report of the Working Party. Copenhagen: Medical Education; 2000.

62. WFME. Basic Medical Education, WFME Global Standards for Quality Improvement. The 2012 Revision. Copenhagen: University of Copenhagen; 2012.

63. Bhutta ZA, Chen L, Cohen J, Crisp N, Evans T, Fineberg $\mathrm{H}$, et al. Education of health professionals for the 21st century: a global independent Commission. Lancet. 2010;375(9721):1137-8.

64. Zakon.hr [homepage on the Internet]. Act on Regulated Professions and Recognition of Foreign Professional Qualifications [in Croatian]
(2015). [cited 2018 March 20]. Available from: https://www.zakon.hr/z/499/Zakon-o-reguliranim-profesijama-i-priznavanju-inozemnih-stru\%C4\%8Dnih-kvalifikacija

65. Vilović K, Jurčević S, Ivanišević R, Sapunar D. Clinical skills teaching - survey at medical schools in Split and Zagreb. Medicina. 2006;42:26-30.

66. Thompson AR, Braun MW, O'Loughlin VD. A comparison of student performance on disciplinespecific versus integrated exams in a medical school course. Adv Physiol Educ. 2013;37(4):3706.

67. Marušić M. Integrated undergraduate and graduate study programme - Medicine [in Croatian]. Split: Medicinski fakultet u Splitu; 2011.

68. Marusic A, Malicki M, Sambunjak D, Jeroncic A, Marusic M. Teaching science throughout the sixyear medical curriculum: two-year experience from the University of Split School of Medicine, Split, Croatia. Acta Med Acad. 2014;43(1):50-62.

69. Tugwell P. The campaign to revitalize academic medicine kicks off: we need a deep and broad international debate to begin. Croat Med J. 2004;45(3):241-2. 